\title{
Reply to the letter
}

\author{
Kunihisa Hotta ${ }^{1}$
}

Received: 18 August 2020 / Accepted: 21 August 2020 / Published online: 30 August 2020

(c) Japanese Society of Anesthesiologists 2020

Keywords COVID-19 $\cdot$ Regional anesthesia $\cdot$ N95 mask

To the Editor:

I appreciate the valuable comments regarding my article [1]. The letter includes important ideas for performing regional anesthesia in patients with COVID-19. Because regional anesthesia is not an aerosol-generating procedure, it is generally considered to be at a lower risk than general anesthesia, which requires airway intervention [2]. However, care should be taken to prevent the transmission of the COVID19 infection even when the patient undergoes surgery under regional anesthesia. The letter reminds us of the importance of infection control not only during surgery but also during regional anesthesia procedures. When performing peripheral nerve block for upper limb surgery or performing neuraxial anesthesia, anesthesiologists and nurses who assist in patient positioning may be close to the patient's face. I agree with the usefulness of using N95 respirators under the oxygen masks on awake patients in the operating room to limit particles.

\section{Compliance with ethical standards}

Conflict of interest The author declares no conflicts of interest associated with this manuscript.

\section{References}

1. Hotta K. Regional anesthesia in the time of COVID-19: a minireview. J Anesth. 2020. https://doi.org/10.1007/s00540-020-02834 $-3$.

2. Tran K, Cimon K, Severn M, Pessoa-Silva CL, Conly J. Aerosol generating procedures and risk of transmission of acute respiratory infections to healthcare workers: a systematic review. PLoS ONE. 2012;7(4):e35797.

Publisher's Note Springer Nature remains neutral with regard to jurisdictional claims in published maps and institutional affiliations.

This reply refers to the comment available online at https://doi. org/10.1007/s00540-020-02850-3.

Kunihisa Hotta

hottak@jichi.ac.jp

1 Department of Anesthesiology and Critical Care Medicine,

Jichi Medical University School of Medicine, 3311-1

Yakushiji, Shimotsuke-shi, Tochigi 329-0498, Japan 